\title{
Estudo das características da produção, comercialização e qualidade de produtos derivados de jabuticaba no município de Sabará-Minas Gerais, Brasil
}

\author{
Nathália de Andrade Neves ${ }^{1}$, Luíza Aparecida Carneiro Fernandes ${ }^{2}$, Maria Emília \\ Rodrigues Valente ${ }^{1}$, Frederico Augusto Ribeiro de Barros ${ }^{3}$, Paulo César Stringheta ${ }^{3}$
}

\begin{abstract}
Resumo: O Festival da Jabuticaba, evento tradicional em Sabará-MG, ocorre graças à Associação dos Produtores de Derivados de Jabuticaba de Sabará (ASPRODEJAS), a qual os membros produzem e comercializam diversas iguarias a partir da fruta. Objetivando conhecer as características de produção, comercialização e o potencial do município para a obtenção de um registro de indicação geográfica $(I G)$, foram aplicados questionários às produtoras e coletadas amostras de geleias e licores para análise da qualidade. Os resultados mostraram uma produção de caráter artesanal e comercialização informal. Alguns dos produtos analisados apresentaram-se fora dos padrões de qualidade estabelecidos na legislação e apresentaram falta de padronização na forma de produção. Os resultados obtidos permitiram concluir que o registro de IG no município é pertinente, embora seja notória a necessidade de investimento em infraestrutura e capacitação técnica para a obtenção de produtos de maior qualidade.
\end{abstract}

Palavras-chave: Plinia jaboticaba. Indicação geográfica. Licor. Geleia.

Área Temática: Associativismo.

\section{Study of the characteristics of the production, commercialization and quality of products derived from jaboticaba in Sabará-Minas Gerais, Brazil.}

\begin{abstract}
The Festival of Jaboticaba, a traditional event in Sabará-MG-Brazil, occurs thanks to the "Sabará'sJaboticaba Derivatives Products Association" (ASPRODEJAS), which members produce and commercialize various delicacies from the fruit. Aiming to know the characteristics of production, commercialization and the potential of the city to obtains a geographical indication register (GI), were applied questionnaires to the producers and were collected samples of jellies and liqueurs for quality analysis. The results showed that the production is artisanal, and the commercialization is informal. Some of the jellies and liqueurs analyzed were out of the quality standards from the legislation and doesn't have any standard in the product quality. From the results, it can be concluded that the creation of a GI seal in Sabará is pertinent, although it is needed investments in infrastructure and technical training to obtain higher quality precuts.
\end{abstract}

Keywords: Pliniajaboticaba. Geographical indication. Liquor. Jelly.

\footnotetext{
${ }^{1}$ Doutoranda do Programa de Ciência e Tecnologia de Alimentos da Universidade Federal de Viçosa - UFV, Viçosa - MG, Brasil. ${ }^{2}$ Graduanda do curso de Engenharia de Alimentos da Universidade Federal de Viçosa- UFV, Viçosa - MG, Brasil.

${ }^{3}$ Professor Doutor do Curso de Engenharia de Alimentos da Universidade Federal de Viçosa- UFV, Viçosa -MG, Brasil. Laboratório de Corantes e Compostos Bioativos. Av. P. H. Rolfs s/n Campus Universitário. Viçosa, MG, 36.570-000, (31) 3612-6711- E-mail: andradeneves.nathalia@gmail.com
} 


\section{Estudio de las características de producción, comercialización y calidad de productos derivados de jabuticaba en el municipio de Sabará-Minas Gerais, Brasil}

Resumen: El Festival de la Jabuticaba, evento tradicional en Sabará-MG, ocurre gracias a la Asociación de Productores de Derivados de Jabuticaba de Sabará (ASPRODEJAS), el cual los miembros producen y comercializan diversos productos a partir de esta fruta. Con el objetivo de conocer las características de producción, comercialización y el potencial del municipio para la obtención de un registro de indicación geográfica (IG), se aplicaron cuestionarios a las productoras y recolectadas muestras de jaleas y licores para análisis de calidad. Los resultados mostraron una producción de carácter artesanal y comercialización informal. Algunas de las jaleas y licores analizados se presentaron fuera de los estándares de calidad establecidos en la legislación y presentaron falta de estandarización en la forma de obtención. Los resultados obtenidos permitieron concluir que la creación de un sello de IG en el municipio es pertinente, aunque es notoria la necesidad de inversión en infraestructura y capacitación técnicas para la obtención de productos de mayor calidad.

Palabras clave: Pliniajaboticaba. Indicación geográfica licor. Jalea.

\section{INTRODUÇÃO}

A jabuticaba é um fruto não climatérico, tipo baga, pequeno, com cascas negras e polpa branca. Sua polpa, muito apreciada pelos consumidores, tem sabor doce e ligeiramente ácido. Composta por carboidratos (glicose e frutose) e fibras como componentes majoritários, possui também vitaminas, flavonoides e minerais (GURAK; BONA; TESSARO; MARCZAK, 2014). O fruto possui ainda alto teor de antocianinas, sobretudo nas cascas, além de derivados de quercetina, miricetina, ácido elágico e metil elágico (NEVES; STRINGHETA; GÓMEZ-ALONSO; HERMOSÍN-GUTIÉRREZ, 2018). A presença desses compostos, com reconhecida capacidade antioxidante, sugere que a jabuticaba possa ser considerada como um alimento funcional (FERNANDES; SILVA, 2018). Recentes estudos mostram que extratos do fruto apresentam propriedade vasodiladora e atuam no controle do estresse oxidativo (ALEZANDRO; GRANATO; GENOVESE, 2013; SÁ et al., 2014; WU; LONG; KENNELLY, 2013).

A jabuticaba é uma fruta tipicamente brasileira, ocorrendo em todo o território nacional, do Pará ao Rio Grande do Sul (HACKE et al., 2016). Segundo dados oficiais do Instituto Brasileiro de Geografia e Estatística (IBGE, 2017), em 2017 o país tinha cerca de 169.460 estabelecimentos agropecuários produtores de jabuticaba. Os principais estados produtores são Goiás e Minas Gerais, possuindo o segundo 57.684 unidades produtoras e 91 mil árvores.

A cidade mineira de Sabará é considerada a cidade da jabuticaba; a espécie (Plinia jaboticaba (DC) Berg.) recebe o nome de jabuticaba sabará em homenagem ao município, onde é endêmica. Segundo os historiadores, a região compreendeu o primeiro povoamento do estado de Minas Gerais, que atraiu bandeirantes paulistas em busca de ouro e pedras preciosas. O nome Sabará, segundo acredita-se, pode ter surgido da palavra Sabarabuçu, ou pedra grande e reluzente (DELVAUX, 2014). A jabuticaba ou Iapoti Kaba, do TupiGuarani, que significa fruto em botão, é nativa da região e era consumida pelos índios desde tempos remotos. Com o povoamento dessa área, os colonizadores passaram a conhecer a fruta e, aos poucos, passaram a 
consumi-la. Acredita-se que os primeiros derivados, como licores e doces de jabuticaba, surgiram logo depois, devido à necessidade de conservação da fruta, que é muito perecível. A elaboração de geleias, licores, vinho, compotas, dentre outros, é atualmente uma tradição no município, que tem sempre seu nome relacionado a esses produtos.

A jabuticaba é considerada o "ouro negro" sabarense, possuindo papel importante na economia local. A cidade de Sabará possui 95 estabelecimentos agropecuários cadastrados como produtores do fruto (IBGE 2017); no entanto, grande parte da produção ocorre dentro da sede do município. Todos os anos, milhares de turistas são atraídos para a cidade na época da safra, entre outubro e dezembro, compreendendo um dos principais atrativos turísticos do município. É comum, nessa época do ano, os visitantes alugarem as jabuticabeiras por um dia ou por algumas horas, consumindo o fruto in natura. O poder público é incentivador dessa tradição, fato evidenciado pela criação de uma lei municipal, em 1983, que fornece um desconto nos Impostos Predial e Territorial Urbano (IPTU) para as propriedades que possuem jabuticabeiras, Lei n ${ }^{\circ} 146 / 82$ e pela criação, em 1987, do Festival de Jabuticaba de Sabará. O festival acontece anualmente na época da safra e abrange a comercialização dos frutos in natura e de produtos processados, bem como da culinária, tendo a jabuticaba como ingrediente. $O$ festival é a data festiva mais importante da cidade, tendo alcançado um público recorde de 120 mil participantes em 2017 (FOLHA DE SABARÁ, 2017).

A elaboração de produtos artesanais de jabuticaba, por ocasião do festival, é realizada por 29 produtoras cadastradas e associadas à ASPRODEJAS (Associação dos Produtores de Derivados de Jabuticaba de Sabará), associação sem fins lucrativos, criada em 2008 com intuito de organizar o festival e regulamentar a participação dos produtores.

Regulamentada no Brasil pela Lei n 9.279 de 14 de maio de 1996 (BRASIL, 1996), a indicação geográfica (IG), nas modalidades Indicação de Procedência (IP) e Denominação de Origem (DO), é utilizada para identificar a origem de produtos ou serviços quando o local tenha se tornado conhecido (IP) ou quando determinada característica ou qualidade do produto ou serviço se deve à sua origem (DO). A indicação geográfica é vantajosa tanto para o consumidor quanto para o produtor. O consumidor tem a garantia de um produto genuíno e notório, cuja qualidade é atrelada à região, seja pelas condições climáticas características do local de origem, seja pelo savoir-faire, conjunto de técnicas tradicionalmente empregadas na elaboração de determinado produto. $\mathrm{O}$ produtor, por sua vez, tem a valorização do seu produto assegurada, bem como de seu patrimônio cultural regional. Embora muito comum nos países europeus, a IG é recente no Brasil, e até 2017 existiam 53 registros no país, entre IP e DO (INPI, 2018).

No entanto, para a obtenção de um selo de IG, existem certos critérios que devem ser observados por parte dos produtores ou prestadores de serviços. Os produtores devem ser organizados em uma entidade representativa, deve haver um regulamento de uso do nome geográfico e a comprovação da existência de uma estrutura de controle, dentre outros (INPI, 2018). Far-se-á importante também a segurança em se oferecer aos 
consumidores um produto de qualidade diferenciada, na qual deseja-se atrelar o nome do município e assim garantir a venda pelo produto per si, vantagem principal de um selo de indicação geográfica.

Uma avaliação criteriosa do estado da arte dos produtos de Sabará é um passo importante antes de se cogitar a possibilidade de obtenção do registro de uma IG para o município. No entanto, a falta de dados oficiais relacionados à produção, comercialização e a qualidade dos produtos elaborados é um fator limitante à essa avaliação.

\section{OBJETIVOS}

O presente trabalho teve por objetivo o estudo das características de elaboração e comercialização de produtos derivados de jabuticaba no município de Sabará, por meio de entrevistas e questionários aplicados aos membros da ASPRODEJAS. Adicionalmente, objetivou-se conhecer a qualidade físico-química dos produtos elaborados, especificamente as geleias e licores, por meio de análises laboratoriais.

\section{METODOLOGIA}

O estudo sobre a elaboração e comercialização de produtos derivados de jabuticaba no município de Sabará foi realizado mediante entrevistas e aplicações de questionários diretamente às produtoras associadas à ASPRODEJAS. A entrevista foi realizada em grupo, uniformemente, e as informações obtidas serviram de base para a elaboração do questionário. Este foi elaborado de forma não estruturada, não disfarçada, no qual os respondentes sabem o objetivo da pesquisa e as perguntas são padronizadas (CARNEVALLI; MIGUEL, 2001). As perguntas contidas no questionário foram relacionadas ao volume de produção, tipos de produtos elaborados, forma de trabalho e motivação.

A aplicação do questionário foi realizada em reunião ordinária da associação, onde estiveram presentes 18 dos 29 membros, constituído somente por mulheres que trabalham na elaboração de produtos derivados de jabuticaba, como forma de diversificar a renda da família. Foi constatado na reunião que a associação não conta ainda com uma sede própria e não possui nenhum tipo de assistência técnica regular. Depois de aplicado o questionário e analisados os resultados, foi realizada uma segunda reunião para a obtenção dos produtos analisados.

A qualidade dos produtos foi avaliada mediante a análises de amostras de licores e geleias de jabuticabas adquiridas diretamente com as produtoras. Esses produtos foram escolhidos pela popularidade e por serem, dentre os produtos derivados de jabuticaba, aqueles com maior tempo de validade, o que os torna potencialmente mais indicados para a expansão do mercado consumidor.

Foram adquiridos um total de 25 geleias e 10 licores de diferentes produtoras e relativos à safra de 2015. As geleias foram analisadas quanto à capacidade antioxidante, pelo método ABTS (RE et al., 1999), pH, por meio de leitura direta em phmêtro, textura, por meio de leitura direta em texturômetro (IENSEN; SANTOS; 
QUAST; QUAST; RAUPP, 2013), teores de antocianinas totais (RIBÉREAU-GAYON; STONESTREET, 1965), compostos fenólicos totais (SHAHIDI; NACZK, 1995) e sólidos solúveis totais, por leitura direta em refratômetro. Os licores foram analisados quanto aos teores de antocianinas totais, compostos fenólicos totais e etanol, seguindo as especificações para análise de vinhos (OIV-INTERNATIONAL ORGANIZATION OF VINE AND WINE, 2018).

Foi avaliada a correlação entre os dados obtidos para teor de antocianinas, compostos fenólicos e etanol, nos licores e textura, $\mathrm{pH}$, teor de sólidos solúveis totais, compostos fenólicos, antocianinas e capacidade antioxidante para as geleias. As análises foram realizadas por meio de correlação de Spearman $(0,05 \%)$, utilizandose o software R Studio, versão 3.5.0.

\section{RESULTADOS E DISCUSSÃO}

\section{Aspectos de produção e comercialização}

A jabuticaba utilizada na elaboração dos produtos é proveniente das zonas urbana e rural do município de Sabará, que corresponde também aos distritos pertencentes ao município, tais como Ravena, Pompeu, dentre outros.

Dentre as entrevistadas, $39 \%$ produzem $100 \%$ da jabuticaba utilizada na elaboração dos seus produtos derivados. A maior parte dessa produção provém de até cinco jabuticabeiras cultivadas nos quintais das próprias casas. Das entrevistadas que não produzem toda a jabuticaba utilizada, 33\% produzem alguma porcentagem e $28 \%$ não produzem nada. Quando proveniente de terceiros, $75 \%$ da jabuticaba utilizada é adquirida diretamente do produtor, no próprio município, sendo o restante recebido diretamente de outros produtores, na forma de doação

Em relação à quantidade da fruta utilizada na elaboração dos produtos, usualmente medida em volume pelas produtoras, $16 \%$ das entrevistadas utilizam menos de $500 \mathrm{~L}$ da fruta, $28 \%$ utilizam entre 500 e $1.000 \mathrm{~L}$, $11 \%$ utilizam entre 1.000 e $2.000 \mathrm{~L}$ e $44 \%$ utilizam mais de $3.000 \mathrm{~L}$. A quantidade de fruta utilizada e, consequentemente, o volume de produtos elaborados, varia de acordo com a disponibilidade de mão-de-obra na época da safra. Segundo as respostas obtidas, a maioria das produtoras trabalha sozinha ou é ajudada por algum membro da família, sobretudo os filhos. A quantidade de pessoas contratadas é baixa, somente $11 \%$ das produtoras contratam só um ajudante.

A comercialização dos produtos ocorre principalmente na ocasião do festival, que é justamente a razão da existência da associação. No entanto, $61 \%$ das entrevistadas declararam comercializar os produtos durante todo o ano, enquanto $33 \%$ comercializam na época da safra e meses subsequentes. Em relação ao mercado, a comercialização é realizada principalmente no município de Sabará e região, durante o festival e em lojas de artesanatos, e não há um local oficial para a comercialização e divulgação do trabalho das associadas. A saída do 
produto para outros estados brasileiros ocorre esporadicamente em vendas realizadas diretamente para o consumidor final. A comercialização dos produtos ao longo de todo o ano depende da sua perecibilidade, sendo que a geleia e o licor são os produtos mais utilizados nesse caso. Além disso, a falta de disponibilidade dos produtos para além da época do festival torna-se um empecilho para a sua comercialização. Tal fato só é possível nos anos em que ocorre a safrinha, uma pequena produção de frutos entre os meses de fevereiro e abril, ou quando a produtora tem capacidade de produção maior, ocasionando em produtos excedentes à época de maior procura. No entanto, a produção de excedentes torna-se difícil devido ao caráter totalmente artesanal da produção, ao curto período de safra e o volume de trabalho nessa ocasião, sendo a produtora responsável por todas as etapas do processo, do processamento à comercialização.

A motivação para a elaboração dos produtos é muito variada, sendo que, dentre as opções fornecidas: tradição de família, oportunidade de utilizar a safra anual, oportunidade de negócio, complemento à renda familiar e forma de colocar em prática os conhecimentos culinários, houve uma homogeneidade na escolha por parte das participantes. Quanto à contribuição da atividade à renda anual da família, 59\% declararam que a atividade contribui em até $25 \%$ da renda, enquanto $35 \%$ declararam que a comercialização dos derivados de jabuticaba corresponde de 25 a $75 \%$ da renda anual da família. Todas as participantes declararam não receber ajuda de assistência técnica regular na elaboração de seus produtos.

Dentre todos os produtos elaborados, os mais populares são a geleia e o licor, sendo produzidos por $100 \%$ das participantes da pesquisa. Em seguida, vem o fermentado alcoólico, chamado popularmente de "vinho", elaborado por $89 \%$ das participantes, e o molho agridoce e a cachaça curtida, produzidos por $83 \%$ das participantes. Dentre esses produtos, somente o molho possui um período de validade mais curto, o que restringe sua comercialização. Além desses produtos, o bombom, doce em compota, suco e bolo recheado também são populares e comercializados exclusivamente na ocasião do festival. A preferência dos consumidores, baseada no volume de venda, é por produtos como: "vinho", geleia e licor.

Segundo o relato das produtoras, existe grande motivação na elaboração e comercialização. A boa aceitação dos consumidores e a competição entre as produtoras, que são premiadas em relação à melhor geleia, são os grandes motivadores, que contribuem para a constante inovação e aperfeiçoamento. Muitas vezes sem contar com o apoio público, elas buscam fazer um festival cada vez melhor, investindo, dentro das possibilidades, na melhoria da qualidade dos produtos. Sendo assim, a intervenção nesse grupo poderia ser realizada de forma fácil, com grande aceitação e abertura por parte da associação. Nota-se ainda que a atividade no município tem grande capacidade de crescimento, tendo em vista a importância e abrangência do festival. A melhoria da qualidade dos produtos, a conquista da indicação geográfica e a saída da informalidade poderiam fazer com que esses produtos alcancem o mercado nacional, trazendo visibilidade e retorno financeiro para a ASPRODEJAS e para o município.

As características edafoclimáticas do local de cultivo, são de extrema importância na garantia da qualidade de produtos como uvas viníferas e cafés (BELLETTI; MARESCOTTI; TOUZARD, 2017). Especialmente em 
vinhos, o conceito de terroir que abrange a combinação de condições pedológicas e climáticas, assim como a cultivar da videira, clone, porta-enxerto e técnicas de viticultura (GONZÁLEZ; PARGA-DANS; VÁZQUEZ, 2017), asseguram a qualidade e distinguem as características dos vinhos produzidos em cada região. Oliveira e colaboradores (2003) estudaram as características físico-químicas de jabuticaba sabará provenientes de dez diferentes regiões do estado de São Paulo e constataram que a região de cultivo exerce influência nas características físico-químicas dos frutos, como tamanho, cor, sabor, acidez, dentre outras. Entretanto, para o presente trabalho, tais variações não são esperadas, uma vez que os frutos utilizados na elaboração dos produtos derivados são originários da mesma região e sob condições de cultivo semelhantes.

Na produção em Sabará, nota-se que há um baixo investimento no processamento da matéria-prima, o que tem levado a um estrangulamento do comércio dos produtos, principalmente quando a demanda aumenta. A falta de investimento no plantio e na manutenção das jabuticabeiras, inovação técnica e comercialização comprometem a produção como um todo. Exemplo disso, há a incerteza da oferta de jabuticabas em safras futuras, sobretudo as produtoras que adquirem a matéria-prima na forma de doação.

A informalidade na produção de produtos derivados de jabuticaba é um fator crítico. Ao visitar Sabará, um consumidor não tem a garantia de encontrar os produtos da região, fora da época do festival, devido à não manutenção de estoques, não planejamento da quantidade de produtos a serem elaborados e até mesmo a falta de um local de comercialização.

\section{Qualidade química de geleias e licores de jabuticaba}

Na Tabela 1 estão dispostos os resultados referentes à caracterização físico-química das geleias de jabuticaba.

As geleias devem atender a algumas características intrínsecas ao produto, como textura, que deve apresentar aspecto de gel, sem escorrer quando retirada da embalagem, macia ao cortar, porém firme, não deve ser açucarada, pegajosa ou viscosa, deve conter cor brilhante e sabor característico da fruta de origem (ABID; YAICH; HITOURI; ATTIA; AYADI, 2018). No entanto, nem todas as geleias analisadas apresentaram tais características. Foi observado que 11 das 25 geleias obtidas não apresentavam o aspecto de gel, escorrendo e até mesmo apresentando aspecto líquido. Essa característica, segundo a legislação brasileira, descaracteriza o produto, que deve apresentar "aspecto de base gelatinosa, de consistência tal, que quando extraídas de seus recipientes, sejam capazes de se manterem no estado semi-sólido" (BRASIL, 1978). Os valores de textura apresentados pelas geleias variaram de 0,244 a 1,310 N. Dentre elas, 22 geleias apresentaram valores abaixo de 1,1 N e 1,26 N, valores de referência encontrados em trabalhos envolvendo geleias de uva (RIBAS; BURATTO; PEREIRA, 2017) e umbu-cajá (OLIVEIRA et al, 2014) respectivamente. Os valores de textura encontrados indicam que as geleias estão fora da textura ideal, como indicado pelas percepções obtidas na análise visual. 
Tabela 1. Caracterização físico-química de geleias de jabuticaba produzidas artesanalmente no município de Sabará-MG.

\begin{tabular}{|c|c|c|c|c|c|c|}
\hline $\begin{array}{c}\text { Amostra de } \\
\text { Geleia }\end{array}$ & $\mathrm{pH}$ & $\begin{array}{c}\text { Textura } \\
(\mathrm{N})\end{array}$ & $\begin{array}{c}\text { Capacidade } \\
\text { antioxidante }\end{array}$ & $\begin{array}{c}\text { Antocianinas } \\
\text { Totais }\end{array}$ & $\begin{array}{c}\text { Compostos } \\
\text { Fenólicos totais }\end{array}$ & $\begin{array}{c}\text { Sólidos Solúveis } \\
\text { Totais }\end{array}$ \\
\hline 1 & 3,43 & 0,417 & 34,604 & 8,904 & 591,153 & 75,0 \\
\hline 2 & 3,55 & 0,257 & 48,205 & 3,645 & 500,409 & 74,5 \\
\hline 3 & 3,14 & 0,287 & 29,604 & 2,218 & 291,728 & 70,6 \\
\hline 4 & 3,68 & 0,417 & 46,853 & 4,882 & 603,362 & 73,0 \\
\hline 5 & 3,45 & 0,363 & 34,843 & 2,276 & 416,619 & 75,1 \\
\hline 6 & 3,40 & 0,338 & 59,808 & 3,841 & 673,805 & 74,6 \\
\hline 7 & 3,18 & 0,555 & 31,034 & 4,263 & 758,454 & 73,7 \\
\hline 8 & 3,63 & 0,457 & 21,119 & 2,949 & 191,249 & 74,9 \\
\hline 9 & 3,23 & 0,282 & 41,952 & 4,162 & 443,636 & 77,7 \\
\hline 10 & 3,51 & 0,401 & 15,140 & 2,540 & 261,481 & 79,3 \\
\hline 11 & 3,11 & 0,507 & 52,786 & 7,916 & 401,673 & 76,4 \\
\hline 12 & 3,26 & 0,795 & 49,554 & 11,270 & 647,617 & 71,0 \\
\hline 13 & 3,31 & 0,817 & 43,934 & 8,715 & 752,622 & 66,3 \\
\hline 14 & 3,46 & 1,405 & 53,977 & 4,014 & 767,459 & 78,7 \\
\hline 15 & 3,19 & 0,244 & 2,851 & 1,971 & 242,849 & 73,1 \\
\hline 16 & 3,46 & 0,332 & 50,312 & 8,714 & 755,053 & 68,8 \\
\hline 17 & 3,23 & 0,312 & 20,246 & 2,641 & 453,413 & 73,7 \\
\hline 18 & 3,43 & 0,397 & 26,801 & 3,071 & 392,632 & 72,4 \\
\hline 19 & 3,38 & 0,586 & 36,969 & 8,585 & 350,649 & 70,7 \\
\hline 20 & 3,40 & 0,445 & 12,916 & 1,592 & 346,911 & 71,1 \\
\hline 21 & 3,39 & 1,310 & 54,120 & 3,444 & 640,627 & 73,0 \\
\hline 22 & 3,31 & 0,614 & 42,753 & 3,812 & 479,647 & 75,1 \\
\hline 23 & 3,30 & 0,658 & 76,779 & 4,157 & 721,106 & 73,1 \\
\hline 24 & 3,10 & 0,635 & 116,041 & 7,653 & 944,861 & 70,8 \\
\hline 25 & 3,14 & 0,716 & 315,640 & 4,527 & 668,34 & 70,1 \\
\hline
\end{tabular}

Fonte: Dados coletados em laboratório pelos próprios autores.

Notas: Capacidade antioxidante expressa em $\mu \mathrm{M}$ de trolox/g de geleia, Antocianinas Totais expressas em mg equivalentes de cianidina-3-glicosídeo/100g de geleia, Compostos Fenólicos Totais expressos em mg equivalentes de ácido gálico /100g de geleia e Sólidos Solúveis Totais expressos em ${ }^{\circ}$ Brix.

As geleias devem atender a algumas características intrínsecas ao produto, como textura, que deve apresentar aspecto de gel, sem escorrer quando retirada da embalagem, macia ao cortar, porém firme, não deve ser açucarada, pegajosa ou viscosa, deve conter cor brilhante e sabor característico da fruta de origem (ABID; YAICH; HITOURI; ATTIA; AYADI, 2018). No entanto, nem todas as geleias analisadas apresentaram tais características. Foi observado que 11 das 25 geleias obtidas não apresentavam o aspecto de gel, escorrendo e até mesmo apresentando aspecto líquido. Essa característica, segundo a legislação brasileira, descaracteriza o 
produto, que deve apresentar "aspecto de base gelatinosa, de consistência tal, que quando extraídas de seus recipientes, sejam capazes de se manterem no estado semi-sólido" (BRASIL, 1978). Os valores de textura apresentados pelas geleias variaram de 0,244 a 1,310 N. Dentre elas, 22 geleias apresentaram valores abaixo de $1,1 \mathrm{Ne}$ 1,26 N, valores de referência encontrados em trabalhos envolvendo geleias de uva (RIBAS; BURATTO; PEREIRA, 2017) e umbu-cajá (OLIVEIRA et al, 2014) respectivamente. Os valores de textura encontrados indicam que as geleias estão fora da textura ideal, como indicado pelas percepções obtidas na análise visual.

A ausência da textura ideal pode ser justificada pelos valores de $\mathrm{pH}$ encontrados. No processo de geleificação envolvendo a pectina, como ocorre na elaboração de geleias de fruta, o pH é decisivo para a formação do gel, devendo estar em torno de 3,0. Valores de $\mathrm{pH}$ acima de 3,4 impedem a geleificação, e abaixo de 2,7 provocam sinérese, ou a exsudação do líquido da geleia (ABID; YAICH; HITOURI; ATTIA; AYADI, 2018; VICENTE, 2016). Nas geleias de jabuticaba analisadas, foram encontrados valores de $\mathrm{pH}$ entre 3,10 e 3,68, sendo que em $36 \%$ delas, os valores encontrados estão acima de 3,4, desfavorecendo a formação da textura desejada.

Outro fator que contribui para a formação do gel é a presença de açúcar na formulação. Concentrações elevadas de açúcares resultam em geleias de consistência pegajosa e favoráveis à formação de cristais, sendo que a concentração ideal é de cerca de 67,5\% (PRASNIEWSKI et al., 2017). Já a legislação brasileira estabelece valores entre 62 e $65 \%$ de sólidos solúveis totais (SST), uma medida indireta da concentração de açúcares. Dentre as geleias estudadas, todas apresentaram valores de SST acima do limite estabelecido. Esse fato sugere a ausência de controle da adição de açúcares, bem como do "ponto" da geleia, durante o processo de redução da formulação.

Embora os valores encontrados para a textura sejam justificados de acordo com os valores de $\mathrm{pH}$ e de SST, não existe uma relação direta entre essas grandezas que possa ser visualizada na análise de correlação (Spearman a 0,05) (Tabela 2).

Tabela 2. Coeficientes de Correlação de Spearman e p valor para os parâmetros avaliados em geleias de jabuticaba produzidas artesanalmente em Sabará-MG

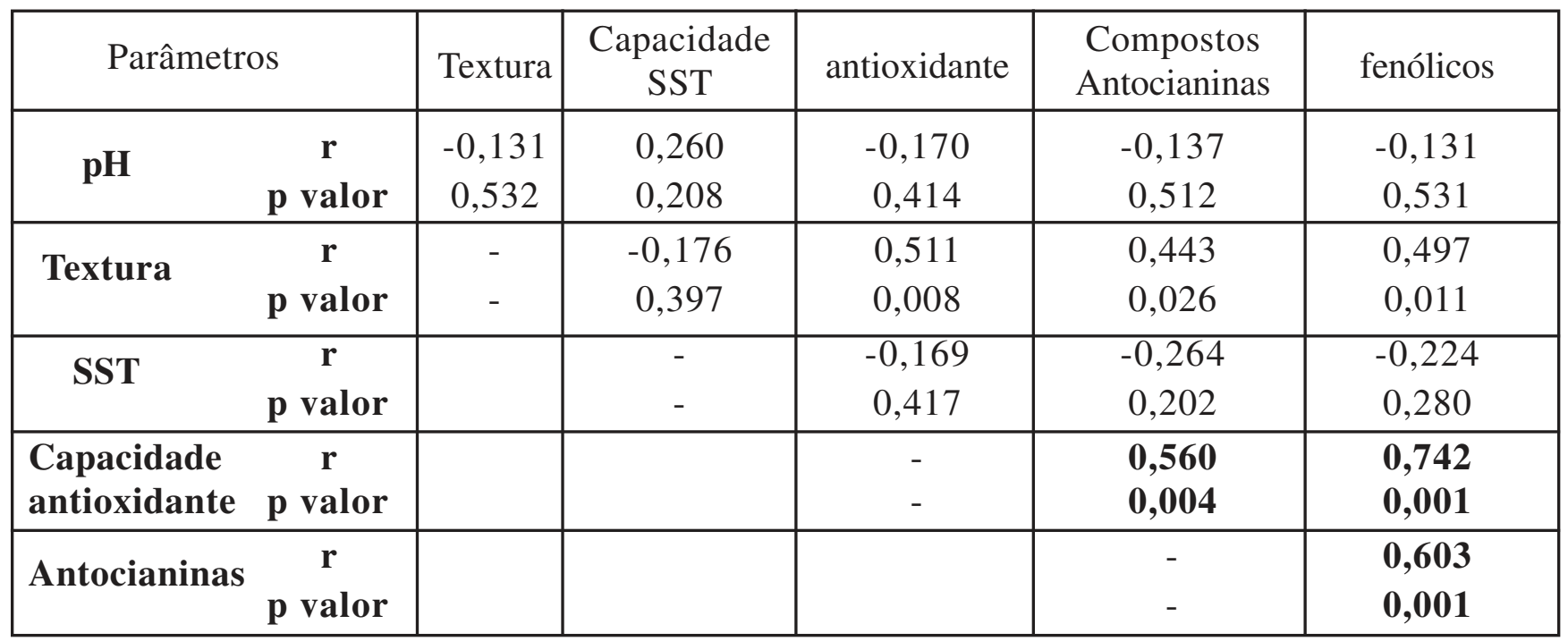

Fonte: Dados coletados pelos próprios autores por meio do software estatístico R.

Notas: Os valores em negrito indicam a existência de correlação linear significativa (Spearman a 0,05). 
As geleias apresentaram valores de antocianinas e compostos fenólicos que variaram de 1,592 a $11,270 \mathrm{mg} / 100 \mathrm{~g}$ de produto e de 246,849 a 944,961 mg/100g, respectivamente. Tal variação pode ter ocorrido a partir de diferentes técnicas empregadas para a elaboração das geleias. Dentre essas variações, destaca-se a quantidade de sacarose acrescentada à formulação, bem como a temperatura e o tempo de cocção, sendo que temperaturas acimas de $90^{\circ} \mathrm{C}$ diminuem sensivelmente o teor de antocianinas. Segundo Dobson e colaboradores (2017), as antocianinas são pigmentos instáveis e se degradam na presença de acidez elevada, açúcares e altas temperaturas, situações encontradas na produção de geleias. Principalmente a antocianina majoritária da jabuticaba (cianidina-3-glicosídeo) que, por ser não metilada, é mais instável do que outras antocianinas, uma vez que a metilação estabiliza o anel fenólico e reduz a reatividade da molécula (NEVES; STRINGHETA; GÓMEZ-ALONSO; HERMOSÍN-GUTIEREZ, 2018). No processo de obtenção de geleias não é possível evitar a polimerização e a degradação de antocianinas, mas a utilização de temperaturas controladas e menores tempos de cocção podem ajudar na degradação excessiva, contribuindo para a valorização do produto.

Quanto à capacidade antioxidante das geleias, observou-se uma variação de 2,851 a 59,80 $\mu \mathrm{M}$ de trolox equivalentes/g de amostra. Os valores encontrados são relativamente baixos em relação a outros produtos de jabuticaba.como extrato da casca $(9458,00 \mu \mathrm{M}$ de trolox equivalentes/g de amostra), extrato do fruto (220,00 $\mu \mathrm{M} / \mathrm{g}$ ), suco $(480,00 \mu \mathrm{M} / \mathrm{g})$ e geleia $(60,00 \mu \mathrm{M} / \mathrm{g})$ (WU; LONG; KENNELLY, 2013). A menor capacidade antioxidante pode estar relacionada à excessiva degradação das antocianinas e demais fenólicos das geleias. Espera-se que a capacidade antioxidante de um alimento seja diretamente proporcional ao teor de compostos fenólicos, especialmente antocianinas. Esse fato é verificado para as geleias estudadas, para as quais há correlação significativa entre os valores encontrados para compostos fenólicos totais e capacidade antioxidante (Tabela 2).

Os resultados discutidos acima sugerem a falta de informações tecnológicas básicas para a elaboração das geleias. Instrumentos simples como balança, termômetro e pHmetro podem auxiliar as produtoras na obtenção de geleias mais padronizadas, com texturas características e maior capacidade antioxidante, conferindo maior qualidade ao produto.

O Artigo 76 do Decreto nº.871, de 4 de junho de 2009, (BRASIL, 2009) determina que "Licor é a bebida com graduação alcoólica de 15 a 54 por cento em volume, a $20^{\circ} \mathrm{C}$, com percentual de açúcar superior a trinta gramas por litro". Metade das amostras de licores obtidas (Tabela 3) possui graduação alcoólica abaixo do mínimo exigido pela legislação, sendo que dois deles possuem teor de etanol inferior a 4\%, o que o desclassifica como bebida alcoólica. O baixo teor de etanol, além de estar em desacordo com a legislação, compromete a qualidade e estabilidade das bebidas, uma vez que o etanol é o constituinte que confere a longevidade característica dos licores, dificultado a proliferação de microrganismos indesejados, além de dissolver os polifenóis e compostos aromáticos, extraindo-os dos frutos e contribuindo para a qualidade sensorial de bebidas alcoólicas. (LIMA, 2009). 
Tabela 3. Caracterização química dos licores de jabuticaba produzidos artesanalmente no município de Sabará-MG

\begin{tabular}{|c|c|c|c|}
\hline $\begin{array}{c}\text { Amostra } \\
\text { de Licor }\end{array}$ & $\begin{array}{c}\text { Teor de Antocianinas } \\
\text { Totais (mg equivalentes } \\
\text { de cy-3-glc/L) }\end{array}$ & $\begin{array}{c}\text { Teor de CompostosFenólicos } \\
\text { Totais (mg equivalentes } \\
\text { de ácido gálico/L) }\end{array}$ & $\begin{array}{c}\text { Teor } \\
\text { Alcoólico } \\
\%(\mathrm{v} / \mathrm{v})\end{array}$ \\
\hline 1 & 85,438 & $8.264,130$ & 1,060 \\
\hline 2 & 76,629 & $7.296,739$ & 15,400 \\
\hline 3 & 62,882 & $2.986,594$ & 1,700 \\
\hline 4 & 49,745 & $3.218,478$ & 18,410 \\
\hline 5 & 66,870 & $6.848,913$ & 4,200 \\
\hline 6 & 56,432 & $1.957,609$ & 13,480 \\
\hline 7 & 57,230 & $5.783,696$ & 15,880 \\
\hline 8 & 32,587 & $3.566,304$ & 17,000 \\
\hline 9 & 76,527 & $9.525,000$ & 4,620 \\
\hline 10 & 40,479 & $2.765,580$ & \\
\hline
\end{tabular}

Fonte: Dados coletados laboratorialmente pelos próprios autores

O processo de produção de licores consiste na impregnação de um líquido, no qual estão contidas elevadas quantidades de etanol, pelos sólidos solúveis presentes na matéria-prima utilizada, acrescido de açúcar em elevadas quantidades (LIMA, 2009). Dessa forma, a concentração de fenólicos totais e antocianinas presentes nos licores de jabuticaba são provenientes do fruto e extraídos pelo etanol. As bebidas que possuem maiores graduações alcoólicas, até certo ponto, tendem a apresentar maiores teores desses compostos (SANTOS, VEGGI; MEIRELES, 2010; VEGGI; SANTOS; MEIRELES, 2011). No entanto, essa característica não foi observada nas amostras de licores estudadas, não havendo correlação entre os teores de antocianinas totais e compostos fenólicos totais com o teor de etanol das bebidas (Tabela 4).

Tabela 4. Coeficientes de Correlação de Spearman e p valor para os parâmetros avaliados em licores de jabuticaba produzidas artesanalmente em Sabará-MG

\begin{tabular}{|c|c|c|c|c|}
\hline \multirow{2}{*}{ Parâmetros } & \multicolumn{2}{|c|}{ Compostos fenólicos } & \multicolumn{2}{c|}{ Etanol } \\
\cline { 2 - 5 } & $\mathrm{r}$ & $\mathrm{p}$ valor & $\mathrm{r}$ & $\mathrm{p}$ valor \\
\hline Antocianinas & $\mathbf{0 , 7 5 7}$ & $\mathbf{0 , 0 1 5}$ & $-0,139$ & 0,707 \\
\hline Compostos fenólicos & - & - & 0,127 & 0,733 \\
\hline
\end{tabular}

Fonte: Dados coletados pelos próprios autores por meio do software R

Notas: Os valores em negrito indicam a existência de correlação linear significativa (Spearman a 0,05).

Vários fatores podem interferir na concentração de compostos fenólicos em bebidas alcoólicas, sobretudo vinhos, como concentrações muito elevadas de etanol, presença de açúcares e de metais, que contribuem para 
a instabilidade desses compostos, sobretudo as antocianinas, que são ainda mais reativas e suscetíveis à polimerização quando livres em meio alcoólico (MAURICIO, ROSADO, FERNANDO, DÍAZ-LANZA, 2018). Levando em consideração o alto teor de etanol e de açúcares normalmente encontrados nos licores, espera-se que ocorra efeito semelhante nesse meio. Assim, os métodos empregados por cada produtora na elaboração dos licores, como tempo de infusão, fonte de etanol, concentração alcoólica e de açúcares, podem ter interferido na extração e estabilidade dos fenólicos das cascas, polpa e sementes de jabuticaba para a bebida final.

Dentre as variações dos métodos de obtenção dos licores, podem ser citadas a fonte de etanol, proporção de frutas por litro de licor produzido, quantidade de açúcar e o tempo de infusão. As matérias-primas tradicionalmente utilizadas na elaboração dos licores são cachaça, álcool de cereais, vodca, conhaque e uísque, sendo o álcool de cereais e a vodca os mais tradicionalmente empregados em licores comerciais (TEIXEIRA, SIMÕES, ROCHA, SARAIVA, \& JUNQUEIRA, 2011). Em licores artesanais utiliza-se majoritariamente o álcool de cereais e a cachaça. A cachaça, apesar de ser muito popular, fácil aquisição e mais barata, não é recomendada para a elaboração de licores porque, apesar de ser eficiente na extração dos aromas da matériaprima, afeta o buquê com componentes secundários que não são eliminados na destilação com alambique, além de ser passível de conter contaminantes como metanol e metais pesados provenientes do processo de destilação (BRAGANÇA, 2013; LIMA, 2009). Os licores artesanais produzidos em Sabará pelas participantes da entrevista são majoritariamente elaborados a partir de cachaça artesanal (58,82\%), enquanto 29,41\% utilizam o álcool de cereais e $11,76 \%$ revezam entre as duas fontes de etanol. As produtoras declararam não haver padronização da matéria-prima, sendo a escolha baseada na oferta e no menor preço.

\section{CONCLUSÕES}

Embora se faça pertinente a obtenção de um selo de identidade geográfica, sobretudo para a geleia e o licor, observa-se que existem alguns pontos falhos em toda a estrutura da ASPRODEJAS, desde a estrutura física, como sede própria e instalações adequadas para a manipulação de alimentos, e na forma de elaboração e comercialização dos produtos.

Além do investimento em infraestrutura, é notória a necessidade de capacitação técnica, que poderia contribuir sobremaneira para a qualidade química, microbiológica e sensorial dos produtos, bem como para o crescimento da ASPRODEJAS. A aquisição de instrumentos simples, como balança, refratômetro, termômetro e etiômetro, e a capacitação quanto à sua utilização podem ser o diferencial na qualidade dos produtos obtidos. Essa melhoria na qualidade é atualmente um fator crítico, devido à tradição e abrangência do festival.

É necessário também o crescimento e a profissionalização da ASPRODEJAS, não só por meio da conquista de uma sede própria, como também no fortalecimento da representatividade da associação junto ao poder público municipal e na comunidade, na busca de parcerias com instituições de fomento e capacitação técnica para a melhoria dos produtos e capacitação para a comercialização. 
Mesmo considerando todos os aspectos críticos apontados, e levando em consideração a tradição e abrangência do festival da Jabuticaba de Sabará, é notório o potencial do município na elaboração e comercialização do fruto de jabuticaba in natura e seus produtos processados. Esse potencial se deve, sobretudo, à tradição e ao nome do município, sempre atrelado ao fruto. Dessa forma, estudos que visem o conhecimento dos aspectos de qualidade dos produtos de jabuticaba são de fundamental importância para a tecnificação e profissionalização da produção e comercialização de derivados de jabuticaba no município, o que, por sua vez, poderá trazer imensos ganhos para o município e para todos os envolvidos nessa atividade.

\section{AGRADECIMENTOS}

Aos membros associados à ASPRODEJAS, pela colaboração, e à Universidade Federal de Viçosa, pela concessão de bolsa de estudos para projeto de extensão.

\section{REFERÊNCIAS}

ABID, M.; YAICH, H.; HIDOURi, H.; ATTIA, H.; AYAD, M. A. Effect of substituted gelling agents from pomegranate peel on colour, textural and sensory properties of pomegranate jam. Food Chemistry, v. 239, n. 15, p. 1047-1054, 2018.

ALEZANDRO, M. R.; GRANATO, D.; GENOVESE, M. I. Jaboticaba (Myrciaria jaboticaba( Vell .) Berg ), a Brazilian grape-like fruit, improves plasma lipid profile in streptozotocin-mediated oxidative stress in diabetic rats. Food Research International, v. 54, p. 650-659, 2013.

BELLETTI, G.; MARESCOTTI, A.; TOUZARD, J. M. Geographical Indications, Public Goods, and Sustainable Development: The Roles of Actors' Strategies and Public Policies. Word Development, v. 98, p. 45-57, 2017.

BRAGANÇA, M. G. L. Licor: Processamento Artesanal. Belo Horizonte: Emater-MG, 2013, 15 p.

BRASIL. Ministério da Saúde. Agência Nacional de Vigilância Sanitária (Anvisa). Resolução CNNPAn 12, de 24 de setembro de 1978. Brasília, DF, 24 de julho de 1978. Sessão 1.

BRASIL. Lei n ${ }^{\circ} 9.279$ de 14 de maio de 1996. Diário Oficial [da] República Federativa do Brasil, Poder executivo, Brasilia, DF, 15 de maio de 1996. Seção 1, p. 8353.

BRASIL. Decreto n6,871 de 4 de junho de 2009. Diário Oficial [da] República Federativa do Brasil, Poder executivo, Brasilia, DF, 5 de junho de 2009. Seção 1, p. 20.

CARNEVALLI, J. A.; MIGUEL, P. A. C. Desenvolvimento da pesquisa de campo, amostra e questionário para realização de um estudo tipo survey sobre a aplicação do qfd no Brasil. ABEPRO (Associação Brasileira de Engenharia de Podrução (2001). Disponível em <http://www.abepro.org.br/biblioteca/ enegep2001_tr21_0672.pdf> Acesso em 11/09/2018. 
DELVAUX, M. M. Fontes de Mitos: sem conhecer o interior da colônia, exploradores recorriam à imaginação. O que os olhos não veem, os cartógrafos desenham. Revista de História da Biblioteca Nacional, n. 103, p. 60-63, 2014.

DOBSON, G.; MCDOUGALL, G. J., STEWART, D.; CUBERO, M. A., KARJALAINEN, R. O. Effects of Juice Matrix and Pasteurization on Stability of Black Currant Anthocyanins during Storage. Journalof Food Science, v. 82, n. 1, 2017.

FERNANDES, L. L.; SILVA, B. M. Alimento funcional: propriedades da jabuticaba. Revista Farol, v. 6, n. 6, p. 49-60, 2018.

FOLHA DE SABARÁ. Melhor de todos os tempos, festival traz a Sabará 120 mil pessoas. Jornal Folha de Sabará. (2017). Disponível em <http://folhadesabara.com.br/noticia/5087>. Acessoem 11/ $09 / 2018$.

GONZÁLEZ, P. A.; PARGA-DANS, E.; VÁZQUEZ, A. M. The political economy of wine: How terroir and intra-sector dynamics affect land use in Spain. Land Use Policy, v. 66, p. 288-292, 2017.

GURAK, P. D.; BONA, G. S.; TESSARO, I. C.; MARCZAK, L. D. F. Jaboticaba Pomace Powder Obtained as a Co-product of Juice Extraction: A Comparative Study of Powder Obtained from Peel and Whole Fruit. Food Research International, v. 62, p. 786-792, 2014.

HACKE, A. C. M.; GRANATO, D.; MACIEL, L. G.; WEINERT, P.; PRADO-SILVA, L.; ALVARENGA, V. O.; SANT'ANA, A. S.; BATAGLION, G. A.; EBERLIN, M. N.; ROSSO, N; D. Jabuticaba (Myrciariacauliflora) Seeds: Chemical Characterization and Extraction of antioxidant and antimicrobial compounds. Journal of Food Science, v. 81, n. 9, p.2206-2217, 2016.

IBGE. CensoAgropecuário 2017. In: IBGE. Sidra: Sistema IBGE de recuperação automática. Disponível em <https://sidra.ibge.gov.br/tabela/1179>. Acesso em 11/09/2018.

IENSEN, D.; SANTOS, I. V.; QUAST, E.; QUAST, L. B.; RAUPP, D. S. Desenvolvimento de Geleia de Kiwi/ : Influência da Polpa, Pectina e Brix na Consistência. UNOPAR Científica. Ciências Biológicas e da Saúde, v. 15, p. 369-375, 2013.

INPI - Instituto Nacional da Propriedade Industrial. Indicação Geográfica no Brasil. Disponível em http://www.inpi.gov.br/menu-servicos/indicacao-geografica/indicacao408 geografica-no-brasil. Acesso em 25/05/2018.

LIMA, U. A. Licores. In W. G. V. Filho (Ed.), Bebidas Alcoólicas, Ciência e Tecnologia de Bebidas $\left(1^{\circ}\right)$. São Paul: Blucher, 2009, 575p.

MAURICIO, E. M.; ROSADO, C.; DUARTE, M. P.; FERNANDO, A. L.; DÍAZ-LANZA, A. M. Evaluation of Industrial Sour Cherry Liquor Wastes as an Ecofriendly Source of Added Value Chemical Compounds and Energy. Waste and Biomass Valorization. https://doi.org/10.1007/s12649018-0395-6, 2018. 
NEVES, N. A.; STRINGHETA, P. C.; GÓMEZ-ALONSO, S.; HERMOSÍN-GUTIÉRREZ, I. Flavonols and ellagic acid derivatives in peels of different species of jabuticaba (Plinia spp.) identified by HPLC-DADESI/MSn. Food Chemistry, v. 252, p. 61-71, 2018.

OIV-INTERNATIONAL ORGANIZATION OF VINE AND WINE. Compendium of International Methods of Wine and Must Analysis. Paris: OIV, 2013, 520 p.

OLIVEIRA, A. L.; BRUNINI, M. A.; SALANDINI, C. A. R.; BAZZO, F. R. Caracterização tecnológica de jabuticabas 'Sabará' provenientes de diferentes regiões de cultivo. Revista Brasileira de Fruticultura, v. 25, n. 2, p; 397-400, 2003.

OLIVEIRA, E. N. A.; SANTOS, D. C.; ROCHA, A. P. T.; GOMES, J. P. Desenvolvimento, caracterização e estabilidade de geleia tradicional de umbu-cajá. Revistra Brasileira de Fruticultura. v. 36, n. 3, p. 640$651,2014$.

R Studio. The R Foundation for StatisticalComputing Platform: x86_64-w64-mingw32/x64 (64-bit).

PRASNIEWSKI, A.; CARTABIANO, C. E.; PEGORINI, D., RONCATTI, R.; PEREIRA, E. A. Aproveitamento tecnológico da casca de jabuticaba na elaboração de geleia. Synergismusscyentifica UTFPR, v. 12, n. 1, p. 74-80, 2017.

RE, R.; PELLEGRINI, N.; PROTEGGENTE, A.; PANNALA, A.; YANG, M.; RICE-EVANS, C. Antioxidanr Activity Applying an Improved ABTS Radical. Free Radical Biology\& Medicine, v. 26, n. 980, p. 1231-1237, 1998.

RIBAS, M. F.; BURATTO, A. P.; PEREIRA, E. A. Desenvolvimento de Geleia de Uva Thompson Seedless. Synergismusscyentifica UTFPR, v. 12, n. 1, p. 109-117, 2017.

RIBÉREAU-GAYON, P.; STONESTREET, E. Le dosage des anthocyanes dans les vins rouges. Bulletin de La Société de Chimie, v. 9, p. 2649-2652, 1965.

SÁ, L. Z. C. M.; CASTRO, P. F. S.; LINO, F. M. A.; BERNARDES, M. J. C.; VIEGAS, J. C. J.; DINIS, T. C. P.; SANTANA, M. L.; ROMAO, W.; VAZ, B. G.; LIÃO, L. M.; GHEDINI, P. C.; ROCHA, M. L.; GIL, E. S. Antioxidant potential and vasodilatory activity of fermented beverages of jabuticaba berry (Myrciariajaboticaba). Journal of Functional Foods, v. 8, n. 1, p. 169-179, 2014.

SANTOS, D. T.; VEGGI, P. C.; MEIRELES, M. A. Extraction of antioxidant compounds from Jabuticaba (Myrciariacauliflora) skins: Yield, composition and economical evaluation. Journal of Food Engineering, $v$. 101, n. 1, p. 23-31, 2010.

SHAHIDI, F.; NACZK, M. Food phenolics: Sources, chemistry, effects, applications. Lancaster; Basel: Technomic, p. 235-273,1995.

TEIXEIRA, L. J. Q.; SIMÕES, L. S.; ROCHA, C. T.; SARAIVA, S. H.; JUNQUEIRA, M. S. Tecnologia, composição e processamento de licores. Enciclopédiabiosfera, v. 7, p.1-17, 2011.

VEGGI, P. C.; SANTOS, D. T.; MEIRELES, M. A. Anthocyanin extraction from Jabuticaba (Myrciariacauliflora) skins by different techniques: economic evaluation. Procedia Food Science, v. 1, p. 1725-1731, 2011. 
VICENTE, E. L. S. Geleia de uva "BRS Violeta" convencional e ligth: Pordução, caracterização e aceitabilidade. 76 f. Dissertação (Mestrado em Agronomia) - Faculdade de Ciências Agronômicas, Universidade Estadual Paulista, Botucatu, 2016.

WU, S. B.; LONG, C.; KENNELLY, E. J. Phytochemistry and health benefits of jaboticaba, an emerging fruit crop from Brazil. Food Research International, v. 54, p. 148-159, 2013.

Submetido em: 19/03/2019 Aceito em: 01/10/2019 